\title{
Bilateral Exudative Retinal Detachment in HELLP Syndrome
}

\author{
C.-L. Schönfeld \\ Augenklinik Herzog Carl Theodor, München, Germany
}

\section{Key Words}

Eclampsia $\cdot$ Exudative $\cdot$ Retinal $\cdot$ Detachment $\cdot$ Bilateral

\begin{abstract}
The HELLP syndrome is a pregnancy complication, life-threatening for mother and child, characterized by hypertension, elevated liver enzymes and low platelets. Blurred vision is the most common visual complaint. A rare case of bilateral exudative retinal detachment associated with the HELLP syndrome is described in a 30-year-old Caucasian woman at 33 weeks' gestation. The retinal detachment did reattach with good improvement in vision under steroid therapy. The case highlights the importance of early involvement of the ophthalmologist when pregnant women complain about visual disorders.
\end{abstract}

\section{Background}

The HELLP syndrome is a disorder during pregnancy characterized by hypertension, hemolysis, elevated liver enzymes and low platelets. Blurred vision is the most common visual complaint, the most frequent ocular finding is arterial narrowing. The syndrome is seen in about $10 \%$ of preeclampsia and eclampsia cases, then causing a high maternal $(3 \%)$ and infantile (24\%) mortality rate [1]. Exudative retinal detachment has been reported in eclampsia [2,3]. Bilateral exudative retinal detachment associated with the HELLP syndrome is rarely reported.

\section{Report of a Case}

A 30-year-old Caucasian woman, gravida III, para II, was seen in the emergency room at 33 weeks' gestation. Her husband mentioned an episode of unconsciousness of about $10 \mathrm{~min}$ in the morning at home. Upon submission, her blood pressure was 190/100 mm Hg. Blood samples were drawn showing the following results: creatinine $144 \mu \mathrm{mol} / \mathrm{l}$ (normal $45-90 \mu \mathrm{mol} / \mathrm{l}$ ), potassium $5.5 \mathrm{mmol} / \mathrm{l}$ (normal 3.5-5.0 mmol/l), platelets $106 \times 10^{9} / \mathrm{l}$ (normal 150-450 × 109/1), leukocytes $23 \times 10^{9} / \mathrm{l}$ 
(normal 4-13.5 × 109/l). Ultrasound revealed no fetal heart rate but a detached placenta. The elevated blood pressure was lowered with 1-2 mg/h nepresol, labor was induced with oxytocin and a dead male infant was delivered. The patient was referred to the intensive care unit where she complained for the first time about blurred vision. Blood samples 1 day postpartum showed a marked increase for creatinine $399 \mu \mathrm{mol} / \mathrm{l}$, potassium $6.5 \mathrm{mmol} / \mathrm{l}$, ALT $24 \mathrm{U} / \mathrm{l}$ (normal 15-22 U/l), AST $119 \mathrm{U} / \mathrm{l}$ (normal for women 4-19 U/l), leukocytes $26 \times 10^{9} / \mathrm{l}$, LDH $860 \mathrm{U} / \mathrm{l}$ (normal 120-240 U/l) and a dramatic decrease in platelets $58 \times 10^{9} / \mathrm{l}$ (normal 140-440 × 109/1), hemoglobin $73 \mathrm{~g} / \mathrm{l}$ (normal 135-180 g/l) and an INR of 2.0 indicating a longer blood coagulation time. Renal failure was diagnosed and hemofiltration was started immediately. The patient was seen by an ophthalmologist on the postpartum day 1 . Her visual acuity was $20 / 40$ in the right (OD) and 20/200 in the left eye (OS) with no afferent pupillary defect. Her anterior segment examination was unremarkable with normal intraocular pressure. Ophthalmoscopic examination revealed bilateral bullous, exudative retinal detachment in the inferior mid periphery to periphery, more extended in the left eye ( $\underline{\text { fig. }}$ ) than in the right eye (fig. 2). The patient received $1.5 \mathrm{mg} / \mathrm{kg}$ body weight/day prednisolone for 3 days to reduce edema, inflammation and vascular permeability, and was positioned upright. Prednisolone was reduced every third day by $20 \mathrm{mg}$. Hemofiltration was performed for 6 days. Visual acuity deteriorated to OD 20/200 and OS to hand movement within the next 4 days. Fluorescein angiography was performed on the postpartum day 9 and showed delayed patchy perfusion of the choroid and multiple focal hyperfluorescent spots in the macula. Visual acuity increased with reattached retina to OD 20/60 and OS 20/40, improving to OD 20/25 and OS 20/30 after 6 months follow-up.

\section{Discussion}

The preeclampsia-eclampsia syndrome can include cardiovascular symptoms, hematologic abnormalities, hepatic and renal impairment and CNS manifestations. The pathogenesis of exudative retinal detachment in eclampsia is not well understood. It is well accepted that the choriocapillaris is damaged by ischemia [4] or thrombosis due to disseminated intravascular coagulation [5]. We think that ischemia is more likely to cause the damage, because in our patient coagulation was extended. Furthermore, we suggest additional ischemic damage to the retinal pigment epithelium, impairing the physiologic pump mechanism. Immediate therapy of the syndrome and delivery of the fetus is advisable to reverse ocular manifestations and avoid visual sequelae. So far, only six cases of bilateral exudative retinal detachment in HELLP syndrome have been reported in the peer-reviewed literature $[3,6-10]$, which highlights the importance to increase awareness of this disorder amongst ophthalmologists. 

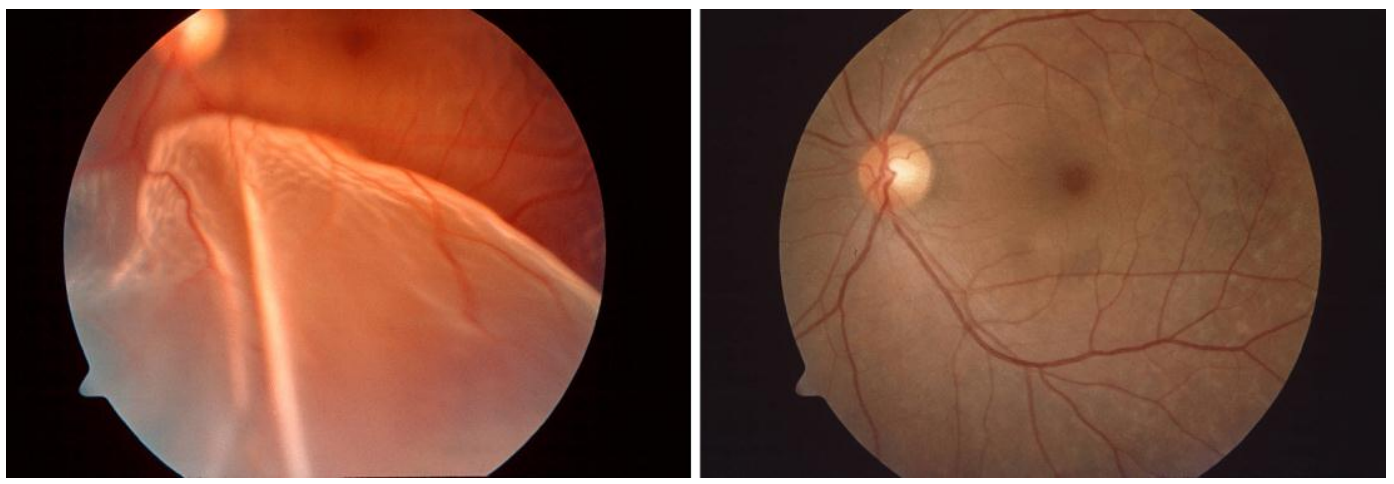

Fig. 1. Fundus photograph of the left eye. Left: bullous exudative retinal detachment at postpartum day 1 in HELLP syndrome. Right: fundus photograph of the same eye at postpartum day 16.
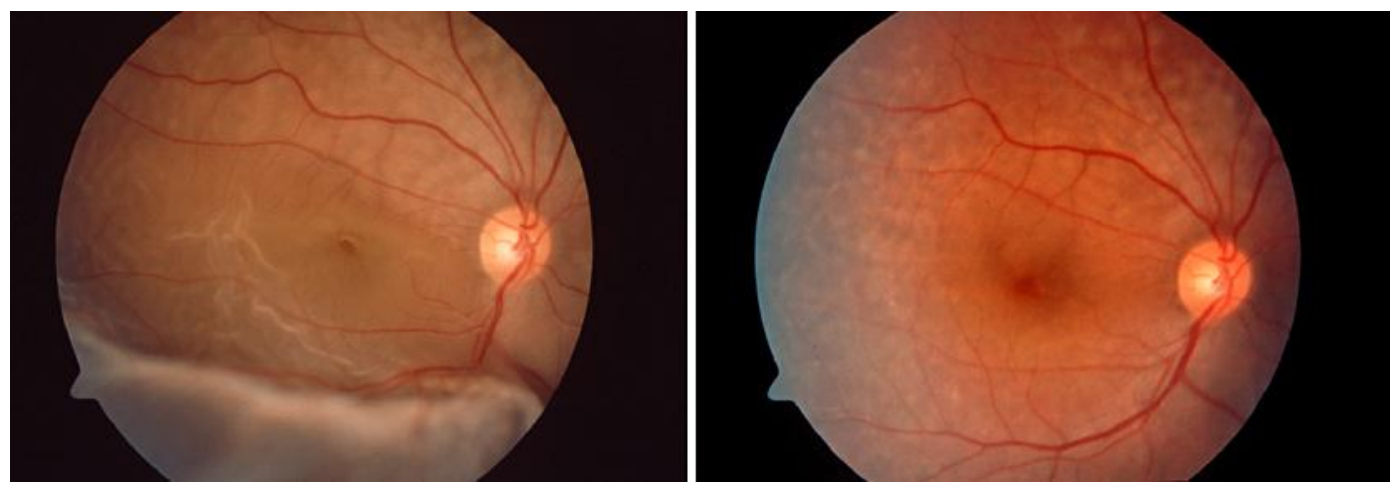

Fig. 2. Fundus photograph of the right eye. Left: bullous exudative retinal detachment at postpartum day 1 in HELLP syndrome. Right: fundus photograph of the same eye at postpartum day 16.

\section{References}

-1 Sibai BM, Taslimi MM, El-Nazer A, Amon E, Mabie B C, Ryan GM Maternal-perinatal outcome associated with the syndrome of hemolysis, elevated liver enzymes, and low platelets in severe preeclampsiaeclampsia. Am J Obstet Gynecol 1986;155:501-509.

-2 Fry WE: Extensive bilateral retinal detachment in eclampsia with complete reattachment: report of two cases. Arch Ophthalmol 1929;1:609-614.

3 Tranos PG, Wickremasinghe SS, Hundal KS, Foster PJ, Jagger J: Bilateral serous retinal detachment as a complication of HELLP syndrome. Eye 2002;16:491-492.

-4 Valluri S, Adelberg DA, Curtis RS, Olk RJ: Diagnostic indocyanine green angiography in preeclampsia. Am J Ophthalmol 1996;122:672-677.

5 Cogan DG: Ocular involvement in disseminated intravascular coagulopathy. Arch Ophthalmol 1975;93:1383-1400.

6 Burke JP, Whyte I, MacEwen CJ: Bilateral serous retinal detachments in the HELLP syndrome. Acta Ophthalmol Scand 1989;67:322-324.

7 Gupta LY, Mansour SE: Bilateral bullous retinal detachment as a complication of the HELLP syndrome. Can J Ophthalmol 1994;29:242-245.

8 Karaguzel H, Guven S, Karalezli A, Erdol H: Bilateral serous retinal detachment in a woman with HELLP syndrome. J Obstet Gynaecol 2009;29:246-248.

9 Mendez-Figueroa H, Davidson C: Bilateral retinal detachments and preeclampsia: thrombotic thrombocytopenic purpura or syndrome of haemolysis, elevated liver enzymes, low platele ts? J Matern Fetal Neonatal Med 2010;23:1268-1270.

10 Kovács EM, Molvarec A, Rigó J Jr, Szabó A: Bilateral serous retinal detachment as a complication of acquired peripartum thrombotic thrombocytopenic purpura bout. J Obstet Gynaecol Res 2011;37:15061509. 